\title{
The expansion of income distribution inequality through globalization: a general equilibrium simulation
}

\author{
$\underline{\text { T. Fukiharu }}^{\text {a }}$ \\ ${ }^{a}$ School of Social Informatics, Aoyamagakuin University \\ Email:fukiharu@si.aoyama.ac.jp
}

\begin{abstract}
The expanded inequality of income distribution has been discussed worldwide, not only in the developing countries but also in the developed ones. We need the theoretical examination as well as the empirical one on this inequality. In the previous paper, Fukiharu (2009) conducted one theoretical examination: whether the inequality expands through ICT innovations. In the present paper, from a different viewpoint the inequality is examined theoretically. This viewpoint is "globalization of economy". In an elementary economics course, the "gains from trade for small country" is taught in such a way that a small country gains by adopting (free) trade. It must be noted that the consumers' surplus increases (decreases) when the producers' surplus decreases (increases), while the increment is always greater than the decrement. This elementary theory with trade-offs between the demander and the supplier is one of the motives in this paper on the expansion of inequality of income distribution through globalization.
\end{abstract}

First, it is examined in terms of simulation approach whether the inequality expands through the globalization of a small country, which possesses small amount of initial endowments of working hours and capital goods compared with the other trading country, utilizing Heckscher-Ohlin model. Heckscher-Ohlin model is an application of general equilibrium theory with trading two countries. First, after production functions, utility functions, and initial endowments are specified randomly, Gini coefficient is computed for the income distribution in a small country, A, isolated from the world economy, in the general equilibrium. A modification is made somewhat into the traditional Heckscher-Ohlin model, in such a way that the two production functions are under decreasing returns to scale, so that positive profit accrues to the entrepreneurs. Thus, there are four consumers of goods: the aggregate workers, the aggregate capitalists, and two entrepreneurs. In this modified model, supposing that the country A opens its economy to a large country B, which possesses large amount of initial endowments of working hours and capital goods, Gini coefficient is computed for the income distribution with the four economic agents in country A, in the general equilibrium with trade. If the former is smaller than the latter, it is defined that the inequality expands through the globalization. Selecting 1000 randomly specified tuples of parameters on Cobb-Doulas type production and utility functions for two countries and initial endowments of working hours and capital goods, selected small for country A and large for country B, we compute the per cent of the inequality expansion cases among the 1000 random selection. Repeating this simulation 20 times, we have the conclusion that out of 1000 simulations, approximately $65 \%$ indicates the country A's expanded inequality of income distribution through globalization. It is also confirmed that the percentage for country A's expanded income distribution cases is approximately $55 \%$ when initial endowments are selected without smallness restriction on country A.

Next, the third commodity is introduced into the basic model. This commodity is a non-traded commodity, while the third production function is also under decreasing returns to scale, so that positive profit accrues to the third entrepreneur. Thus, there are five consumers of goods: (aggregate) workers, (aggregate) capitalists, and three entrepreneurs. Utilizing the same simulation approach, we examine what is the percentage of expanded inequality case among the 1000 simulations. By the similar approach, the result is that approximately $55 \%$ out of 1000 simulations indicates the expansion.

Finally, we examine how the percentage changes when the third commodity is a traded commodity. By the similar approach, the result is that approximately $61 \%$ out of 1000 simulations indicates the expansion. In this way, we may conclude that the globalization has a clear tendency to expand the income distribution inequality when a trading country is small, however small the effect might be.

Keywords: General Equilibrium, Gini coefficient, Income distribution, Heckscher-Ohlin Model, Simulation 


\section{INTRODUCTION}

As developing countries, such as China and India, attained the economic development, the inequality of income distribution has been discussed. This theme was also discussed, theoretically as well as empirically, in the United States by Krugman (2007). In the previous paper, Fukiharu (2009) conducted theoretical examination: whether the inequality expands through ICT innovations. In this paper, this theme is examined theoretically with the focus on the globalization, utilizing Heckscher-Ohlin model.

Traditional Heckscher-Ohlin model is an application of general equilibrium theory for the two-commoditytwo-factor-of-production economy with trading two countries, A and B. In this paper, in order to examine the income distribution, a modification is made somewhat into the traditional model, in such a way that the two production functions are under decreasing returns to scale, so that positive profit accrues to the entrepreneurs. Thus, there are four consumers of goods: the aggregate workers, the aggregate capitalists, and two entrepreneurs. In this modified model, first, Gini coefficient is computed for the income distribution with four economic agents when country $\mathrm{A}$ is in autarkic general equilibrium. Next, supposing that the country $\mathrm{A}$ opens its economy to country B, Gini coefficient is computed for the income distribution with four economic agents in a country $\mathrm{A}$, in the general equilibrium with trade. If the former is smaller than the latter, it is defined that the income inequality expands through the globalization. It must be noted that in this paper, a simulation approach is adopted to compute the Gini coefficient: specifying parameters in Cobb-Doulas type production and utility functions for two countries and initial endowments of working hours and capital goods, selected for country A and for country B, we compute country A's general equilibrium incomes for the four economic agents and compared Gini coefficients.

Starting from this basic four-economic-agent model we proceed to the five-economic-agent model by introducing the third commodity produced by labor and capital. First, we assume that this commodity is a non-traded commodity produced and consumed only in country A. Extending the four economic agents model to the five-economic-agent model: the aggregate workers, the aggregate capitalists, and three entrepreneurs, we examine whether the income inequality in country A expands. Further modifying the assumption in such a way that the third commodity is a traded commodity produced and consumed in both countries, we examine whether the income inequality in country A expands compared with the non-traded commodity case.

\section{THE FOUR-ECONOMIC-AGENT MODEL}

\subsection{Basic Heckscher-Ohlin Model under Decreasing Returns}

Formally, there are two countries, A with two sectors and B with two sectors. The production functions for the two countries regarding the two industries are assumed to be of the same Cobb-Douglas type, where the one for the first sector is $y=f_{1 \mathrm{~A}}\left[L_{1}, K_{1}\right]=f_{1 \mathrm{~B}}\left[L_{1}, K_{1}\right]=L_{1}{ }^{a 1} K_{1}{ }^{b 1}$, the one for the second sector is $x=f_{2 \mathrm{~A}}\left[L_{2}, K_{2}\right]=$ $f_{2 \mathrm{~B}}\left[L_{2}, K_{2}\right]=L_{2}{ }^{a 2} K_{2}^{b 2}$ where $y$ is the output of the first industry, $x$ is the second industry's output, $L_{i}$ is the $i$ th industry's labor input, $K_{i}$ is the $i$ th industry's capital input, and $a_{i}+b_{i}<1(i=1,2)$. It is assumed that country A is initially endowed with $L_{\mathrm{eA}}$ units of Labor and $K_{\mathrm{eA}}$ units of capital, while country B is initially endowed with $L_{\mathrm{eB}}$ units of Labor and $K_{\mathrm{eB}}$ units of capital. In this section, specifying parameters, first, we compute general equilibrium, GE, for country $\mathrm{A}$ in national isolation, proceeding to the computation of Gini coefficient for this "no trade GE" income distribution. Next, supposing that country A trades with country B, we compute the Gini coefficient for the country A's "trade GE" income distribution, examining whether income distribution becomes more unequal or not. For the computation of Gini coefficient, we refer to Layard and Walters (1978).

It may be expected that when $L_{\mathrm{eA}}$ and $K_{\mathrm{eA}}$ are sufficiently smaller than $L_{\mathrm{eB}}$ and $K_{\mathrm{eB}}$ the income distribution might become more unequal. This expectation is based on the elementary theory in economics. According to an arbitrary elementary textbook on economics when a small country opens its economy to the world, the "gains from trade" accrues to the small country. It must be noted, however, that the consumers' surplus increases while the producers' surplus decreases when the world price is lower than the small country's domestic price, whereas the consumers' surplus decreases while the producers' surplus increases when the world price is higher. Thus, this trade-off leads to the above expectation on the income distribution.

\subsection{No-Trade General Equilibrium}

In this subsection, general equilibrium for country $\mathrm{A}$ is examined, when she does not engage herself with trade. From the profit maximization of the sector 1 , demand for labor, $L_{1}{ }^{\mathrm{D}}\left[p_{y}, w_{L}, w_{K}\right]$, and demand for capital, $K_{1}{ }^{\mathrm{D}}\left[p_{y}, w_{L}, w_{K}\right]$, can be analytically computed, where $p_{y}$ stands for the price of the consumption good, 
$y, w_{L}$, wage rate of labor, and $w_{K}$, rental price of capital. From these functions, the supply function of $y, y^{\mathrm{S}}\left[p_{y}\right.$, $\left.w_{L}, w_{K}\right]$, and profit function of sector $1, \pi_{1}\left[p_{y}, w_{L}, w_{K}\right]$, are computed. This profit accrues to entrepreneur 1 , the entrepreneur in sector 1 . From the profit maximization of the sector 2 , demand for labor, $L_{2}^{\mathrm{D}}\left[p_{x}, w_{L}, w_{K}\right]$, and demand for capital, $K_{2}{ }^{\mathrm{D}}\left[p_{x}, w_{L}, w_{K}\right]$, can be analytically computed, where $p_{x}$ stands for the price of the consumption good, $x$. From these functions, the supply function of $x, x^{\mathrm{S}}\left[p_{x}, w_{L}, w_{K}\right]$, and profit function of sector $2, \pi_{2}\left[p_{x}, w_{L}, w_{K}\right]$, are computed. This profit accrues to entrepreneur 2 , the entrepreneur in sector 2 .

All the agents in this paper: workers, capitalists, and entrepreneurs 1 and 2, have the same Cobb-Douglas utility function, $u[y, x]=y^{a} x^{b}$. All the consumers maximize utility subject to income constraint:

$\max u[y, x]$ s.t. $p_{y} y+p_{x} x=m$

where $m$ is income. Worker's income consists of initial endowment of labor, evaluated by the wage rate: $w_{L} L_{\mathrm{eA}}$. It is assumed that they supply $L_{\mathrm{eA}}$ for labor supply. Capitalist's income consists of initial endowment of capital, evaluated by the rental price of capital: $w_{K} K_{\mathrm{eA}}$. It is assumed that they supply $K_{\mathrm{eA}}$ for capital supply. Entrepreneur 1's income consists of profit for the sector 1, $\pi_{1 \mathrm{~A}}$. Finally, entrepreneur 2's income consists of profit for the sector $2, \pi_{2 \mathrm{~A}}$.

From the consumers' optimization, demand function of workers for commodity $y, y_{L}^{\mathrm{D}}\left[p_{y}, p_{x}, w_{L}\right]$, that for commodity $x, x_{L}^{\mathrm{D}}\left[p_{y}, p_{x}, w_{L}\right]$, demand function of capitalists for commodity $y, y_{K}^{\mathrm{D}}\left[p_{y}, p_{x}, w_{K}\right]$, that for commodity $x, x_{K}^{\mathrm{D}}\left[p_{y}, p_{x}, w_{K}\right]$, demand function of entrepreneur 1 for commodity $y, y_{\mathrm{E} 1}^{\mathrm{D}}\left[p_{y}, p_{x}, w_{L}, w_{K}\right]$, that for commodity $x, x_{\mathrm{E} 1}^{\mathrm{D}}\left[p_{y}, p_{x}, w_{L}, w_{K}\right]$, demand function of entrepreneur 2 for commodity $y, y_{\mathrm{E} 2}{ }^{\mathrm{D}}\left[p_{y}, p_{x}, w_{L}\right.$, $\left.w_{K}\right]$, and, that for commodity $x, x_{\mathrm{E} 2}^{\mathrm{D}}\left[p_{y}, p_{x}, w_{L}, w_{K}\right]$, are derived.

General equilibrium for country A without trade, "no trade GE", is defined by the existence of $\left\{p_{y}, p_{x}, w_{L}\right.$, $\left.w_{K}\right\}$, which satisfies the following.

$$
\begin{aligned}
& y_{L}{ }^{\mathrm{D}}[\ldots]+y_{K}{ }^{\mathrm{D}}[\ldots]+y_{\mathrm{E} 1}{ }^{\mathrm{D}}[\ldots]+y_{\mathrm{E} 2} \mathrm{D}[\ldots]=y^{\mathrm{S}}[\ldots] \\
& x_{L}{ }^{\mathrm{D}}[\ldots]+x_{K}{ }^{\mathrm{D}}[\ldots]+x_{\mathrm{E} 1}{ }^{\mathrm{D}}[\ldots]+x_{\mathrm{E} 2}[\ldots]=x^{\mathrm{D}}[\ldots] \\
& L_{1}{ }^{\mathrm{D}}[\ldots]+L_{2}{ }^{\mathrm{D}}[\ldots]=L_{\mathrm{eA}}, \\
& K_{1}{ }^{\mathrm{D}}[\ldots]+K_{2}{ }^{\mathrm{D}}[\ldots]=K_{\mathrm{eA}} .
\end{aligned}
$$

As is well known, by the Walras law, 4 conditions, (1) (4), are not independent. Thus, assuming $w_{L}=1$, we compute "no trade GE" prices: $p_{y}{ }^{*}, p_{x}{ }^{*}$, and $w_{K}{ }^{*}$, as a solution to (1) (3).

Specifying parameters randomly as in what follows, we can analytically compute $p_{y}{ }^{*}, p_{x}{ }^{*}$, and $w_{K}{ }^{*}$.

$$
a_{1}=1 / 6, b_{1}=1 / 5, a_{2}=1 / 4, b_{2}=1 / 3, L_{\mathrm{eA}}=100, K_{\mathrm{eA}}=50, a=3, b=2 \text {. }
$$

Under (5), we have

$$
p_{y}{ }^{*=10} 2^{19 / 30} 3^{3 / 5} 5^{4 / 15} 19^{1 / 5}, p_{x}^{*=4} 2^{1 / 12} 5^{1 / 2} 19^{1 / 3} \text {, and } w_{K}{ }^{*=38 / 15}
$$

Naturally, it can be confirmed that (6) satisfies (4). Furthermore, under (5), economic agents' incomes are computed as in what follows.

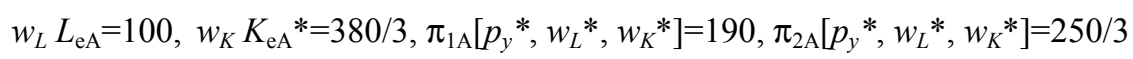

The Gini coefficient corresponding to (7), gini $0^{*}$, is computed as in what follows.

$$
\text { gini } 0 *=0.17333 \text {. }
$$

\subsection{General Equilibrium with Trade: Trade $G E$}

In this subsection country A's trade with country B is introduced. Country B is initially endowed with labor, $L_{\mathrm{eB}}$, and capital, $K_{\mathrm{eB}}$. By assumption, country B's production and utility functions are the same as in country A. The initial endowments of labor and capital are specified in this subsection as in what follows.

$$
L_{\mathrm{eB}}=500, K_{\mathrm{eB}}=50 \text {. }
$$

Corresponding to country A's demand and supply functions, such as $y_{L}^{\mathrm{D}}\left[p_{y}, p_{x}, w_{L}\right]$ etc., country B's domestic demand and supply functions can be computed as $y_{L B}{ }^{\mathbf{D}}\left[p_{y B}, p_{x B}, w_{L B}\right], y_{K B}{ }_{\mathbf{D}}^{\mathbf{D}}\left[p_{y B}, p_{x B}, w_{K B}\right], y_{\mathrm{E} 1 \mathrm{~B}} \mathbf{D}\left[p_{y B}, p_{x B}, w_{L B}\right.$, $\left.w_{K B}\right], y_{\mathrm{E} 2 \mathrm{~B}} \mathbf{D}\left[p_{y B}, p_{x B}, w_{L B}, w_{K B}\right], x_{L B}{ }^{\mathbf{D}}\left[p_{y B}, p_{x B}, w_{L B}\right], x_{K B} \mathbf{D}\left[p_{y B}, p_{x B}, w_{K B}\right], x_{\mathrm{E} 1 \mathrm{~B}} \mathbf{D}\left[p_{y B}, p_{x B}, w_{L B}, w_{K B}\right], x_{\mathrm{E} 2 \mathrm{~B}} \mathbf{\mathbf { D }}\left[p_{y B}, p_{x B}\right.$, $\left.w_{L B}, w_{K B}\right], y_{\mathrm{B}} \mathrm{S}\left[p_{y B}, w_{L B}, w_{K B}\right], x_{\mathrm{B}}{ }^{\mathrm{S}}\left[p_{x B}, w_{L B}, w_{K B}\right], L_{1 \mathrm{~B}}^{\mathrm{D}}\left[p_{y B}, w_{L B}, w_{K B}\right], L_{2 \mathrm{~B}}^{\mathrm{D}}\left[p_{x B}, w_{L B}, w_{K B}\right], K_{1 \mathrm{~B}} \mathrm{D}\left[p_{y B}, w_{L B}, w_{K B}\right]$, and $K_{2 \mathrm{~B}}^{\mathrm{D}}\left[p_{x B}, w_{L B}, w_{K B}\right]$ with $p_{y B}, p_{x B}, w_{L B}, w_{K B}$ as the corresponding price parameters.

In examining general equilibrium with trade, modification must be made. First, we must introduce the import and export of country A (B). Let $y^{\mathrm{E}}\left(x^{\mathrm{I}}\right)$ be country A's export (import) of commodity $y(x)$. For country B, let 
Fukiharu, The expansion of income distribution inequality through globalization

$y_{\mathrm{B}}^{\mathrm{I}}\left(x_{\mathrm{B}}^{\mathrm{E}}\right)$ be country B's import (export) of commodity $y(x)$, where at trade equilibrium $y^{\mathrm{E}}=y_{\mathrm{B}}{ }^{\mathrm{I}}$ and $x^{\mathrm{I}}=x_{\mathrm{B}}^{\mathrm{E}}$ must hold.

General equilibrium for country A with trade, "trade GE", is defined by the existence of $\left\{p_{y}, p_{x}, w_{L}, w_{K}, w_{L B}\right.$, $\left.w_{K B}, y^{\mathrm{E}}, x^{\mathrm{I}}\right\}$, which satisfies (3), (4), and the following.

$$
\begin{aligned}
& y_{L}{ }^{\mathrm{D}}[\ldots]+y_{K}^{\mathrm{D}}[\ldots]+y_{\mathrm{E} 1}^{\mathrm{D}}[\ldots]+y_{\mathrm{E} 2}{ }^{\mathrm{D}}[\ldots]+y^{\mathrm{E}}=y^{\mathrm{S}}[\ldots] \\
& x_{L}^{\mathrm{D}}[\ldots]+x_{K}^{\mathrm{D}}[\ldots]+x_{\mathrm{E} 1}^{\mathrm{D}}[\ldots]+x_{\mathrm{E} 2}{ }^{\mathrm{D}}[\ldots]-x^{\mathrm{I}}=x^{\mathrm{S}}[\ldots] \\
& y_{L B} \mathrm{D}[\ldots]+y_{K B}^{\mathrm{D}}[\ldots]+y_{\mathrm{E} 1 \mathrm{~B}} \mathrm{D}[\ldots]+y_{\mathrm{E} 2 \mathrm{~B}} \mathrm{D}[\ldots]-y^{\mathrm{E}}=y_{\mathrm{B}}^{\mathrm{S}}[\ldots] \\
& x_{L B}^{\mathrm{D}}[\ldots]+x_{K B} \mathrm{D}[\ldots]+x_{\mathrm{E} 1 \mathrm{~B}} \mathrm{D}[\ldots]+x_{\mathrm{E} 2 \mathrm{~B}} \mathrm{D}[\ldots]+x^{\mathrm{I}}=x_{\mathrm{B}} \mathrm{S}[\ldots] \\
& L_{1 \mathrm{~B}}^{\mathrm{D}}[\ldots]+L_{2 \mathrm{~B}}^{\mathrm{D}}[\ldots]=L_{\mathrm{eB}} \\
& K_{1 \mathrm{~B}}^{\mathrm{D}}[\ldots]+K_{2 \mathrm{~B}}^{\mathrm{D}}[\ldots]=K_{\mathrm{eB}} \text {. } \\
& p_{x} x^{\mathrm{I}}=p_{y} y^{\mathrm{E}} \text {. }
\end{aligned}
$$

Note that since decreasing returns to scale is assumed for the production, the factor price equalization theorem does not hold in this paper. The equalization theorem essentially depends on the constant returns to scale assumption.

Under (5) and (9), utilizing the Newton method, we can compute $\left\{p_{y}^{* *}, p_{x}^{* *}, w_{K}^{* *}, w_{L B}{ }^{* *}, w_{K B}{ }^{* *}, y^{\mathrm{E} * *}\right.$, $\left.x^{\mathrm{I} * *}\right\}$ as in what follows. First, from (4), (10), (11), (12), (13),(15), and (16), the Newton method computes the candidate for "trade GE".

$$
\begin{aligned}
& p_{y}{ }^{* *}=86.7884, p_{x}{ }^{* *}=24.4527, w_{K}^{* *}=2.52342, w_{L B}{ }^{* *=}=0.28284, \\
& w_{K B}{ }^{* *}=3.59256, x^{\mathrm{I} *}=0.730083, y^{\mathrm{E} * *}=0.205701
\end{aligned}
$$

It is confirmed that (17) is indeed the "Trade GE" by showing that (17) satisfies (4) and (14). Under (5) and (9), economic agents' incomes are computed as in what follows.

$$
\begin{aligned}
& w_{L}^{* *} L_{\mathrm{eA}}=100, w_{K}^{* *} K_{\mathrm{eA}}=126.171, \pi_{1 \mathrm{~A}}\left[p_{y}{ }^{* *}, w_{L}^{* *}, w_{K}^{* *}\right]=204.133, \\
& \pi_{2 \mathrm{~A}}\left[p_{y}{ }^{* *}, w_{L}{ }^{* *}, w_{K}{ }^{* *}\right]=77.1345
\end{aligned}
$$

The Gini coefficient corresponding to (18), gini $1 * *$, is computed as in what follows.

$$
\operatorname{gini} 1 * *=0.200599 \text {. }
$$

From the comparison between (8) and (19) we may conclude that under (5) and (9) the income distribution becomes more unequal by the globalization.

\subsection{Simulations}

The conclusion in the previous section essentially depends on the specification of parameters. Under specification different from (5) and (9), income distribution may well become more equal by the globalization. In this subsection, we start a simulation with no restriction on the initial endowments of two countries. We proceed to a different simulation with the assumption of country A as a small country.

\subsubsection{Simulation 1: When Country $A$ is not a Small Country}

In this simulation parameters on production and utility functions and initial endowments are selected randomly from arbitrarily selected intervals. For example, parameters for $a_{1}, b_{1}, a_{2}$ and $b_{2}$ are rational numbers selected randomly so that $a_{1}+b_{1}<1$ and $a_{2}+b_{2}<1$. Parameters for $a$ and $b$ are natural numbers selected randomly from the closed interval, [1, 100]. Parameters for $L_{\mathrm{eA}}, L_{\mathrm{eB}}, K_{\mathrm{eA}}$, and $K_{\mathrm{eB}}$ are natural numbers selected randomly from the closed interval, [1, 1000]. From 1000 tuples of $\left\{a_{1}, b_{1}, a_{2}, b_{2}, a, b, L_{\mathrm{eA}}\right.$, $\left.L_{\mathrm{eB}}, K_{\mathrm{eA}}, K_{\mathrm{eB}}\right\}$, selected in this way, we compute the percent of cases in which the income distribution becomes more unequal by the globalization. Computation program is provided in Fukiharu and Choi (2009). Repeating this procedure 20 times, we have the following result.

$54.6463,57.4156,57.91,54.2446,54.3509,53.8244,55.6522,51.8519,53.4682,53.505$,

$56.5657,53.6797,55.5233,58.7719,56.0563,54.3228,58.2621,53.8462,54.507,53.1818$

Approximately, 55\% indicates that the income distribution becomes more unequal by the globalization.

\subsubsection{Simulation 2: When Country $A$ is a Small Country}

In this simulation, parameters for $a_{1}, b_{1}, a_{2}$ and $b_{2}$ are selected as rational numbers randomly so that $a_{1}+b_{1}<1$ and $a_{2}+b_{2}<1$. Parameters for $a$ and $b$ are natural numbers selected randomly from the closed interval, [1, 100]. However, we assume that country A is a small country compared with country B. Thus, parameters for $L_{\mathrm{eA}}$ and $K_{\mathrm{eA}}$ are natural numbers selected randomly from the closed interval, [1, 100], while parameters for 
Fukiharu, The expansion of income distribution inequality through globalization

$L_{\mathrm{eB}}$ and $K_{\mathrm{eB}}$ are natural numbers selected randomly from the closed interval, [900, 1000]. From 1000 tuples of $\left\{a_{1}, b_{1}, a_{2}, b_{2}, a, b, L_{\mathrm{eA}}, L_{\mathrm{eB}}, K_{\mathrm{eA}}, K_{\mathrm{eB}}\right\}$, selected in this way, we compute the percent of cases in which the income distribution becomes more unequal by the globalization. Repeating this procedure 20 times, we have the following result.

$69.697,68.0697,67.6829,67.8354,65.3846,66.6667,65.2047,66.8693,64.8286,63.9818$,

$70.5701,70.9677,67.0165,66.1267,66.5158,66.311,67.2205,66.1383,64.723,64.8256$

Approximately, more than $65 \%$ indicates that the income distribution becomes more unequal by the globalization. When country A is a small country she has stronger tendency to become more unfair society by the globalization, compared with the result in the previous subsection.

\section{THE FIVE-ECONOMIC-AGENT MODEL}

In this section, the third commodity is introduced into the original Heckscher-Ohlin model, for the purpose of deepening the examination conducted so far, especially examining the difference of conclusions for the two cases: case 1, in which the commodity is a non-traded commodity, and case 2, in which the commodity is a traded commodity. We have five economic agents in this section, since entrepreneur 3 is introduced.

\subsection{Case1: When the Third Commodity is Non-Traded}

\subsubsection{No-Trade General Equilibrium}

It is assumed that the third commodity, $z$, is produced by labor and capital under decreasing returns to scale, with the production function expressed as the Cobb-Douglas type: $z=f_{3 \mathrm{~A}}\left[L_{3}, K_{3}\right]=L_{3}{ }^{a 3} K_{3}{ }^{b 3}, a_{3}+b_{3}<1$. In this subsection, it is assumed that this commodity is produced only in country A and it is non-traded. In country A, by the profit maximization, entrepreneurs have $y^{\mathrm{S}}\left[p_{y}, w_{L}, w_{K}\right], x^{\mathrm{S}}\left[p_{x}, w_{L}, w_{K}\right], z^{\mathrm{S}}\left[p_{z}, w_{L}, w_{K}\right], L_{1}^{\mathrm{D}}\left[p_{y}, w_{L}\right.$, $\left.w_{K}\right], L_{2}{ }^{\mathrm{D}}\left[p_{x}, w_{L}, w_{K}\right], L_{3}{ }^{\mathrm{D}}\left[p_{z}, w_{L}, w_{K}\right], K_{1}^{\mathrm{D}}\left[p_{y}, w_{L}, w_{K}\right], K_{2}{ }^{\mathrm{D}}\left[p_{x}, w_{L}, w_{K}\right]$, and $K_{3}{ }^{\mathrm{D}}\left[p_{z}, w_{L}, w_{K}\right]$ with $p_{y}, p_{x}, p_{z}, w_{L}$, $w_{K}$ as the corresponding price parameters where $p_{z}$ is the price of $z$. By the following utility maximization under budget constraint, the consumers have demand functions: $y_{L}^{\mathrm{D}}\left[p_{y}, p_{x}, p_{z}, w_{L}\right], y_{K}^{\mathrm{D}}\left[p_{y}, p_{x}, p_{z}, w_{K}\right], y_{\mathrm{E} 1}^{\mathrm{D}}\left[p_{y}\right.$, $\left.p_{x}, p_{z}, w_{L}, w_{K}\right], y_{\mathrm{E} 2}{ }^{\mathrm{D}}\left[p_{y}, p_{x}, p_{z}, w_{L}, w_{K}\right], y_{\mathrm{E} 3}{ }^{\mathrm{D}}\left[p_{y}, p_{x}, p_{z}, w_{L}, w_{K}\right], x_{L}^{\mathrm{D}}\left[p_{y}, p_{x}, p_{z}, w_{L}\right], x_{K}^{\mathrm{D}}\left[p_{y}, p_{x}, p_{z}, w_{K}\right], x_{\mathrm{E} 1}^{\mathrm{D}}\left[p_{y}, p_{x}\right.$, $\left.p_{z}, w_{L}, w_{K}\right], x_{\mathrm{E} 2}{ }^{\mathrm{D}}\left[p_{y}, p_{x}, p_{z}, w_{L}, w_{K}\right], x_{\mathrm{E} 3}{ }^{\mathrm{D}}\left[p_{y}, p_{x}, p_{z}, w_{L}, w_{K}\right]$.

$\max u[y, x, z]=y^{a} x^{b} z^{c}$ s.t. $p_{y} y+p_{x} x+p_{z} z=m$.

General equilibrium for country A without trade, "no trade GE", is defined by the existence of $\left\{p_{y}, p_{x}, p_{z}, w_{L}\right.$, $\left.w_{K}\right\}$, which satisfies the following.

$$
\begin{aligned}
& y_{L}^{\mathrm{D}}[\ldots]+y_{K}^{\mathrm{D}}[\ldots]+y_{\mathrm{E} 1}{ }^{\mathrm{D}}[\ldots]+y_{\mathrm{E} 2}{ }^{\mathrm{D}}[\ldots]+y_{\mathrm{E} 3}{ }^{\mathrm{D}}[\ldots]=y^{\mathrm{S}}[\ldots] \\
& x_{L}[\ldots]+x_{K}^{\mathrm{D}}[\ldots]+x_{\mathrm{E} 1}{ }^{\mathrm{D}}[\ldots]+x_{\mathrm{E} 2}[\ldots]+x_{\mathrm{E} 3}[\ldots]=x^{\mathrm{D}}[\ldots] \\
& z_{L}{ }^{\mathrm{D}}[\ldots]+z_{K}^{\mathrm{D}}[\ldots]+z_{\mathrm{E} 1}[\ldots]+z_{\mathrm{E} 2}[\ldots]+z_{\mathrm{E} 3}[\ldots]=z^{\mathrm{D}}[\ldots] \\
& \left.L_{1}^{\mathrm{D}}[\ldots]+L_{2}[\ldots]+\ldots\right]+L_{3}^{\mathrm{D}}[\ldots]=L_{\mathrm{e}}[\ldots, \\
& K_{1}{ }^{\mathrm{D}}[\ldots]+K_{2}[\ldots]+K_{3}[\ldots]=K_{\text {eA }}[\ldots
\end{aligned}
$$

In order to compute actual Gini coefficient, the following specification is added arbitrarily.

$$
a_{3}=1 / 2, b_{3}=1 / 4, c=4 \text {. }
$$

Under (5), (9), and (25), from (20) (23) we can analytically compute "no trade GE" as in what follows.

$$
\begin{aligned}
& p_{y}{ }^{\circ}=102^{5 / 6} 3^{-7 / 30} 5^{4 / 15} 17^{1 / 5}, p_{x}^{\circ}=42^{5 / 12} 5^{1 / 2} 17^{1 / 3} 3^{-3 / 4}, p_{z}^{\circ}=42^{1 / 2} 85^{1 / 4} 3^{-3 / 4}, \\
& w_{K}{ }^{\circ}=68 / 45
\end{aligned}
$$

Naturally, (26) satisfies (24). Utilizing (26), we compute Gini coefficient as in what follows.

$$
\operatorname{gini} 0^{\circ}=0.248889 \text {. }
$$

\subsubsection{Trade General Equilibrium}

In examining "trade GE", it suffices to modify only (20) and (21) to the following, respectively.

$$
\begin{aligned}
& y_{L}^{\mathrm{D}}[\ldots]+y_{K}^{\mathrm{D}}[\ldots]+y_{\mathrm{E} 1}{ }^{\mathrm{D}}[\ldots]+y_{\mathrm{E} 2} \mathrm{D}[\ldots]+y_{\mathrm{E} 3} \mathrm{D}[\ldots]+y^{\mathrm{E}}=y^{\mathrm{S}}[\ldots] \\
& x_{L} \mathrm{D}[\ldots]+x_{K}^{\mathrm{D}}[\ldots]+x_{\mathrm{E} 1} \mathrm{D}[\ldots]+x_{\mathrm{E} 2}[\ldots]+x_{\mathrm{E} 3}[\ldots]-x^{\mathrm{D}}=x^{\mathrm{S}}[\ldots]
\end{aligned}
$$

Thus, under (5), (9), and (25), by applying Newton method on (12), (13), (15), (16), (22), (24), (28), and (29) we can compute "trade GE" as in what follows.

$$
p_{y}{ }^{\circ \circ}=41.0529, p_{x}^{\circ \circ}=12.0907, p_{z}^{\circ \circ}=7.53189, w_{K}^{\circ \circ}=1.48935, w_{K B}^{\circ \circ}=1.75075 \text {, }
$$


Fukiharu, The expansion of income distribution inequality through globalization

$$
w_{L B}{ }^{\circ \circ}=0.137539, y^{\mathrm{E} \circ \circ}=0.376588, x^{\mathrm{I} \circ \circ}=1.27867 .
$$

Naturally, (30) satisfies (14) and (23).

The Gini coefficient corresponding to $(30)$, gini $1^{\circ \circ}$, is computed as in what follows.

$$
\operatorname{gini} 1^{\circ \circ}=0.259743 \text {. }
$$

From the comparison between (27) and (31) we may conclude that under (5), (9), and (25) the income distribution becomes more unequal by the globalization.

\subsection{Simulation 3}

In this simulation, parameters for $a_{1}, b_{1}, a_{2}, b_{2}, a_{3}$, and $b_{3}$, are rational numbers selected randomly so that $a_{i}$ $+b_{i}<1(i=1,2,3)$. Parameters for $a, b$, and $c$ are natural numbers selected randomly from the closed interval, $[1,100]$, respectively. Furthermore, we assume that country A is a small country compared with country B. Thus, parameters for $L_{\mathrm{eA}}$ and $K_{\mathrm{eA}}$ are natural numbers selected randomly from the closed interval, [1, 100], while parameters for $L_{\mathrm{eB}}$ and $K_{\mathrm{eB}}$ are natural numbers selected randomly from the closed interval, [900, 1000]. From 1000 tuples of $\left\{a_{1}, b_{1}, a_{2}, b_{2}, a_{3}, b_{3}, a, b, c, L_{\mathrm{eA}}, L_{\mathrm{eB}}, K_{\mathrm{eA}}, K_{\mathrm{eB}}\right\}$, selected in this way, we compute the percent of cases in which the income distribution becomes more unequal by the globalization. Computation program is provided in Fukiharu and Sun (2010). Repeating this procedure 20 times, we have the following result.

$56.743,56.6667,56.9948,55.4707,58.7796,57.5096,55.1298,53.5939,55.9301,54.633,55.4707$, $57.1608,56.015,57.8815,54.9367,58.875,56.5968,55.8052,58.802,55.7882$

Approximately, 55\% indicates that the income distribution becomes more unequal by the globalization. Result in this simulation is rather similar to Simulation 1. Note that the percentage is clearly lower than the one in Simulation 2. The income distribution, however, becomes more unequal by the globalization.

\subsection{Case 2: When the Third Commodity is Traded}

\subsubsection{No-Trade General Equilibrium}

It is assumed in this subsection that the third commodity is also produced in country B and it is traded between the two countries. There is no need, however, to repeat the analysis in 3.1.1. We have exactly the same conclusions: (26) and (27).

\subsubsection{Trade General Equilibrium}

In this subsection, country B also produces the third commodity, so that her entrepreneur 3 has demand and supply functions: $z_{\mathrm{B}}^{\mathrm{S}}\left[p_{z}, w_{L B}, w_{K B}\right], L_{3 \mathrm{~B}}^{\mathrm{D}}\left[p_{z}, w_{L B}, w_{K B}\right]$, and $K_{3}^{\mathrm{D}}\left[p_{z}, w_{L B}, w_{K B}\right]$ with $p_{y}, w_{L B}$, and $w_{K B}$ as the corresponding price parameters. Consumers in country $\mathrm{B}$ also have demand functions for the third commodity: $z_{L B}{ }^{\mathrm{D}}\left[p_{y}, p_{x}, p_{z}, w_{L B}\right], z_{K B}{ }^{\mathrm{D}}\left[p_{y}, p_{x}, p_{z}, w_{K B}\right], z_{\mathrm{E} 1 \mathrm{~B}}{ }^{\mathrm{D}}\left[p_{y}, p_{x}, p_{z}, w_{L B}, w_{K B}\right], z_{\mathrm{E} 2 \mathrm{~B}}{ }^{\mathrm{D}}\left[p_{y}, p_{x}, p_{z}, w_{L B}, w_{K B}\right]$, and $z_{\mathrm{E} 3 \mathrm{~B}}{ }^{\mathrm{D}}\left[p_{y}, p_{x}, p_{z}, w_{L B}, w_{K B}\right]$.

In examining general equilibrium, first, (22) must be modified to incorporate her import of $z: z^{\mathrm{I}}$.

$$
z_{L}^{\mathrm{D}}[\ldots]+z_{K}^{\mathrm{D}}[\ldots]+z_{\mathrm{E} 1}^{\mathrm{D}}[\ldots]+z_{\mathrm{E} 2}{ }^{\mathrm{D}}[\ldots]+z_{\mathrm{E} 3}^{\mathrm{D}}[\ldots]-z^{\mathrm{I}}=z^{\mathrm{S}}[\ldots]
$$

Meanwhile, equilibrium condition for the third commodity in country B must be added and country B's commodity, labor, and capital market equilibrium conditions must be modified, as well as trade equilibrium condition, as in what follows

$$
\begin{aligned}
& z_{L B}{ }^{\mathrm{D}}[\ldots]+z_{K B}{ }^{\mathrm{D}}[\ldots]+z_{\mathrm{E} 1 \mathrm{~B}}{ }^{\mathrm{D}}[\ldots]+z_{\mathrm{E} 2 \mathrm{~B}}{ }^{\mathrm{D}}[\ldots]+z_{\mathrm{E} 3 \mathrm{~B}} \mathrm{D}[\ldots]+z^{\mathrm{I}}=z_{\mathrm{B}}{ }^{\mathrm{S}}[\ldots] \\
& y_{L B}{ }^{\mathrm{D}}[\ldots]+y_{K B} \mathrm{D}[\ldots]+y_{\mathrm{E} 1 \mathrm{~B}} \mathrm{D}[\ldots]+y_{\mathrm{E} 2 \mathrm{~B}} \mathrm{D}[\ldots]+y_{\mathrm{E} 3 \mathrm{~B}} \mathrm{D}[\ldots]-y^{\mathrm{D}}=y_{\mathrm{B}}{ }^{\mathrm{S}}[\ldots] \\
& x_{L B} \mathrm{D}[\ldots]+x_{K B} \mathrm{D}[\ldots]+x_{\mathrm{E} 1 \mathrm{~B}} \mathrm{D}[\ldots]+x_{\mathrm{E} 2 \mathrm{~B}} \mathrm{D}[\ldots]+x_{\mathrm{E} 3 \mathrm{~B}} \mathrm{D}[\ldots]+x^{\mathrm{D}}=x_{\mathrm{B}}{ }^{\mathrm{D}}[\ldots] \\
& L_{1 \mathrm{~B}} \mathrm{D}[\ldots]+L_{2 \mathrm{~B}} \mathrm{D}[\ldots]+L_{3 \mathrm{~B}}[\ldots]=L_{\mathrm{DB}}[\ldots] \\
& K_{1 \mathrm{~B}} \mathrm{D}[\ldots]+K_{2 \mathrm{~B}} \mathrm{D}[\ldots]+K_{3 \mathrm{~B}} \mathrm{D}[\ldots]=K_{\mathrm{eB}} . \\
& p_{x} x^{\mathrm{I}}+p_{z} z^{\mathrm{I}}=p_{y} y^{\mathrm{E}} .
\end{aligned}
$$

Under (5), (9), and (25), by applying Newton method to (24), (28), (29), (32) (35), (37), and (38) we can compute "trade GE" as in what follows.

$$
\begin{aligned}
& p_{y}{ }^{\circ *}=50.378, p_{x}{ }^{\circ *}=16.8194, p_{z}{ }^{\circ *}=7.28165, w_{K}{ }^{\circ *=}=1.77292, w_{K B}{ }^{\circ *=2.98005}, \\
& w_{L B}{ }^{\circ *}=0.42907, y^{\mathrm{E} \circ *}=0.702611, x^{\mathrm{I} \circ *=}-1.29855, z^{\mathrm{I} \circ *=7.86045} .
\end{aligned}
$$

Naturally, (39) satisfies (23) and (36). 
Fukiharu, The expansion of income distribution inequality through globalization

The Gini coefficient corresponding to (36), gini $1^{\circ *}$, is computed as in what follows.

$$
\operatorname{gini} 1^{\circ} *=0.23362 \text {. }
$$

From the comparison between (27) and (40) we may conclude that under (5), (9), and (25) the income distribution becomes more equal by the globalization.

\subsubsection{Simulation 4}

From 1000 tuples of $\left\{a_{1}, b_{1}, a_{2}, b_{2}, a_{3}, b_{3}, a, b, c, L_{\mathrm{eA}}, L_{\mathrm{eB}}, K_{\mathrm{eA}}, K_{\mathrm{eB}}\right\}$, selected in exactly the same way as in Simulation 3, we compute the percent of cases in which the income distribution becomes more unequal by the globalization. Computation program is provided in Fukiharu (2011). Repeating this procedure 20 times, we have the following result.

63.3094, 59.1463, 63.581, 65.6212, 59.9757, 59.4238, 63.1953, 64.9573, 63.0105, 59.5238, 58.313, $62.8954,62.5899,65.7831,63.7349,61.9976,63.6695,62.9131,63.2406,64.415$

Approximately, slightly greater than $60 \%$ indicates that the income distribution becomes more unequal by the globalization. Note that this percentage is clearly greater than the one in Simulation 3. In any way, the income distribution becomes more unequal by the globalization.

\section{CONCLUSIONS}

This paper examined if the income distribution inequality of a country expands through her globalization, somewhat modifying traditional 2-country-2-commodity-Heckscher-Ohlin model. The modification consists in assuming decreasing returns to scale on production functions, so that entrepreneurs with positive profit, owners of the firms, become consumers. In section 2, with 2 industries (commodities), there are 4 consumers: the (aggregate) worker, the (aggregate) capitalist, and 2 entrepreneurs. It was shown that there is a tendency for the inequality to expand, by simulation approach: i.e. $55 \%$ of the 20000 cases, in which parameters are selected randomly, indicated that inequality expands when a country in isolation, say A, begins her trade with other country, say B. Furthermore, when country A is small compared with country B, $65 \%$ indicated that the inequality in country A expands by opening trade with country $\mathrm{B}$. In section 3 , the third industry (commodity) is introduced, so that there are 5 consumers. It is assumed that country A is small. It was shown that when the third commodity is produced only in country A and is a non-traded commodity, only $55 \%$ of the 20000 cases indicated that inequality expands when country A in isolation begins her trade with country B. It was shown, however, that when the third commodity is produced in both countries and is a traded commodity, more than $60 \%$ of the 20000 cases indicated that inequality expands when country A in isolation begins her trade with country B. Thus, we may conclude that there is a clear tendency for the inequality to expand through the globalization, however weak the effect might be.

\section{ACKNOWLEDGMENTS}

The author appreciates the financial support provided by the Grants-in-Aid for Science Research (Contract Number: 22530181).

\section{REFERENCES}

Fukiharu, T. (2004). A Simulation of the Heckscher-Ohlin Theorem. Mathematics and Computers in Simulation, 64, 161-168.

Fukiharu, T. (2009). Information and Communication Technologies and the Income Distribution: A Simulation through Inequality Measures. 18th World IMACS Congress and MODSIM09 International Congress on Modelling and Simulation. July 2009, 1404-1410.

Fukiharu, T., and I.J. Choi (2009). Globalization and Income Distribution Inequality in Heckscher-Ohlin Model I: A Simulation for Small Country Case. http://home.hiroshima-u.ac.jp/fukito/index.htm.

Fukiharu, T. , and J.N. Sun (2010). Globalization and Income Distribution Inequality in Heckscher-Ohlin Model II: A Simulation for Small Country Case with Non-Traded Good”.

http://home.hiroshima-u.ac.jp/fukito/index.htm

Fukiharu, T. (2011). Globalization and Income Distribution Inequality in Heckscher-Ohlin Model III: A Simulation for Small Country Case with Three Traded Goods.

http://www.cc.aoyama.ac.jp/ fukito/IndexII.htm

Krugman, P. (2007). The Conscience of a Liberal. W.W. Norton \& Company, NYC.

Layard, P.R.G. and A.A. Walters (1978). Microeconomic Theory, McGraw-Hill Book, U.K. 